\title{
The Status of Pesticides in China and Their Future*
}

\author{
Da-Xiang WANG \\ Shen-Yang Research Institute of Chemical Industry, Shen-Yang, Liao-Ning Province, China
}

Agriculture is very important in the economy of China and the life of the Chinese people. The climatic condition of China is very diverse and there are numerous kinds of crops planted in different areas throughout the country. Injuries caused by insects, fungus and weeds are very complicated problems, and for this reason plant protection is most important in the development of agriculture and forests. Pesticides have played an important role in the protection of crops from inroads made by pests.

In ancient times natural products such as minerals and herbs were used to control insects in China. The use of arsenic oxide for the control of soil insects was recorded in books written long ago.

The development of chemical pesticides was started after the founding of the People's Republic of China in 1949. Insecticides were developed first, and then fungicides and herbicides. During the past 30 years the production and application of pesticides has developed quickly. The total amount of pesticides produced until 1980 was 537,000 tons/year. Those pesticides produced and used have approximately met plant protection requirements, but to assure further agricultural development more pesticides must be developed.

\section{STATUS OF PESTICIDES IN CHINA}

\section{Insects and Insecticides}

There are many types of insects that infest agricultural plants and crops and forests. Among these, $i_{\text {nsects }}$ with biting mouthparts and with sucking mouthparts are most important to control. Lepidopterous insects are the most harmful of those with biting mouthparts; for example, rice stem borers, including Chilo suppresalis and Tryporyza, are very injurious insects to paddy rice. In field crops corn borer, soybean pod borer, cotton bollworm, pink bollworm and armyworm are the most harmful. Fruit borer and leaf roller on fruit trees and cabbage moth and white and sulfur butterflies on vegetables are very harmful. All of these mentioned are Lepidoptera. In addition,

* A speech given at the 6th Annual Meeting of the Pesticide Science Society of Japan there are many other types which are also harmful to crops, such as Chafer (Scarabaeidae), plant bug (Miridae), rice leafhopper and planthopper. Injuries caused by soil insects are also a serious problem in agriculture. The mole cricket, cutworm and false wireworm are common in China. Among insects with sucking mouthparts, aphids and spider mites cause the most damage to field crops, vegetables and fruit trees.

Overall in China from the standpoint of plant protection, insect injury is currently a more serious problem that fungus or weeds. As a result, the development of insecticides has been faster than that of fungicides or herbicides. Insecticides account for a large percentage of the total amount of pesticides produced.

When pesticides were first used, some inorganic chemicals were used for plant protection. Arsenic oxide was used for soil insect control and lead arsenate and calcium arsenate were also used in agriculture. Recently, however, these types of insecticides have not been used. During the past twenty years the main insecticides used in China have been organic compounds.

\section{a. Organic chlorine compounds}

Organic insecticide production in China started from organic chlorine compounds. BHC and DDT have been produced since the early 1950s and used to control housefly and mosquitoes; a few years following their introduction these two insecticides were used in agriculture. For a long time, BHC and DDT played an important role in plant protection in China. For example, locusts used to attack field crops in a large area along the Yellow River in such numbers that the infestations caused disaster for the people living there. During the 1950s great success was achieved in the control of locusts by BHC sprayed by airplane; since that time locust infestations have been eliminated. For control of insects such as the stem borer in paddy rice fields, $\mathrm{BHC}$ has been used for many years and has proven very effective. Cotton and soil insects have also been controlled by these insecticides. However, due to the wide use of $\mathrm{BHC}$ and DDT, a pollution problem has 
developed in China and has been brought to the attention of the government.

In technical $\mathrm{BHC}$, there are large amounts of alfaand beta-isomers which do not affect insects but are harmful to the environment. In order to decrease the side effects of these isomers and to utilize them, technical $\mathrm{BHC}$ has been purified to $90 \%$ gammaisomer or Lindane. The alfa- and beta-isomers separated from technical $\mathrm{BHC}$ have been utilized to produce such substances as hexachlorobenzene, pentachlorophenol and pentachloronitrobenzene. The by-product of DDT, $p$-chlorobenzenesulfonic acid, has been used to produce TDN.

In China there is a large amount of turpentine oil from which Toxaphene has been produced and used. Chlordane has also been produced on a small scale.

b. Organic phosphorous compounds

Organic phosphorous insecticides have been produced and used for many years, both singly or in a mixture with other insecticides. In 1956 parathion was put into production as the first organic phosphorous insecticide. Since then, the variety and quantity of organic phosphorous insecticides has increased annually.

Parathion and methyl-parathion mixed with BHC have been used in paddy rice for the control of stem borer as well as in other fields.

More than ten years ago systox was produced and used for aphid and spider mite control, but production and application were stopped after a few years due to its high mammalian toxicity. Thimet was first produced for seed dressing to control soil insects and is still used in some crops for seed treatment.

During the past twenty years, many organic phosphorous insecticides with low mammalian toxicity have been produced, such as malathion, trichlorfon and dimethoate, dichlorvos, imidan, fenitrothion, phoxim, monocrotophos, and acephate. These insecticides have been widely used on food crops, vegetables and fruit trees.

\section{c. Other insecticides}

Just as in Japan, after the control of stem borer in paddy rice, rice leafhopper and planthopper became annually more serious. For this reason some carbamates such as MPMC and MTMC have been produced in China and this type of insecticide has become more and more important. For control of cotton insects, carbaryl has also been produced. TDN and dicofol were produced and used for spider mite control, in addition to organic phosphorous acaricides. For food grain storehouse treatment, zinc phosphide, chloropicrin and methyl bromide have been produced and used widely. Recently some pyrethroids have also been put into production on a small scale.

\section{Plant Disease and Fungicides}

There are many kinds of plant diseases that infest crops, vegetables and fruits, and such diseases are also enemies of agriculture and forestry. In paddy rice fields the main plant diseases are rice blast, sheath blight and bacterial leaf blight. These diseases are always serious, especially in the southern part of China, and they are also occasionally found in northern China. In wheat, rust, wheat scab and smuts are the main diseases, and in other crops, sorghum smut, corn smut and downy mildew are problems. In cotton, damping-off and Fusarium rot are very injurious. Downy mildew, powdery mildew, scabs apple canker and many kinds of blights (especially Phytophthora infestans) are the main diseases of fruit trees and vegetables.

To control these various diseases, fungicides were developed. At the beginning, inorganic compounds such as copper sulfate, colloidal and limesulfur were put into production. In the mid-1950s some factories began to produce organic sulfur fungicides. Zineb, amobam, captan and phaltan date back to that time and have been widely used on vegetables, fruit trees and other food crops. Sodium $p$-aminobenzenesulphonate, dexon and other fungicides have also been industrialized and used. Organic mercury compounds were used until ten years ago, at which time they were banned because of their mammalian toxicity. Organic arsenic compounds, such as zinc methylarsenate, ammonium ferric methyl-arsenate and tuzet were widely used during 1960-1970, but now only tuzet is still used in some limited areas. Since the beginning of the 1970s, some organic phosphorous fungicides such as kitazin and hinozan have been used for the control of rice blast. The systemic fungicides carbendazim, thiophanate and carboxin have also been produced for about ten years and have increased annually in quantity.

Antibiotics are very important in plant disease control and agricultural use antibiotics have played an important role in China's plant protection. Jienggang-mei-su is an antibiotic like Validamycin; the producer (Streptomyces) was isolated from the soil of the Jieng-gang mountain. This antibiotic has been produced on a large scale and widely used, especially for the control of rice sheath blight. Kasugamycin and blasticidins have also been produced and used.

\section{Weeds and Herbicides}

Agricultural weeding is done mainly by band or machine, but herbicides are also used in broad areas. During the past fifteen years the production of the latter has developed gradually. Weeds in field crops and paddy fields in China are quite similar to those in Japan and some other foreign countries. In paddy fields, barnyard-grass, nutgrass, dayflower and some 
other grasses as well as broadleaf weeds are the main problems. In field crops, barnyard-grass, dog's tooth grass, crabgrass and wild oat are the most harmful weeds.

The first kind of herbicides produced in China were phenoxyacetic acids. 2,4-D and MCPA were produced and used for weed control in wheat during the early stages of herbicide use. Triazine herbicides, simazine and atrazine, as well as substituted urea herbicides, diuron and chlotoluron, were then produced on a small scale. Recently trifluralin and alachor have been imported as experimental herbicides for weed control in corn and soybean fields. For wild oat control, di-allate and tri-allate were used and new wild oat controlling herbicides are now under field trial.

Herbicidal weed control in rice fields has been carried out in many provinces for many years. During the 1960s pentachlorophenol was used in paddy fields, but was taken out of use a few years later because of its high toxicity to fish. Since then nitrofen has been the most popular herbicide used in paddy fields. Propanil and swep have been used for seed beds and, in recent years, thiobencarb (benthiocarb) has been imported from Japan for paddy field weed control. In addition, 2,4-D has been used as a plant growth regular as have naphthylacetic acid, gibberellin and CCC. Recently an experiment carried out using Krenite to regulate the growth of cotton, oranges and rubber trees gave some very interesting and hopeful results.

\section{SOME OPINIONS OF THE FUTURE OF PESTICIDES IN CHINA}

Here, I would like to say a few words on my own point of view on the future of the development of pesticides in China.

As is known to all, agriculture holds an important position in China's economy and is responsible for the food supply for about one billion people. For its rapid development, it is essential to produce a large amount of pesticides for plant protection. I believe that pesticides should be developed step by step to a new level.

Integrated pest control is the main policy of China's plant protection; however, chemical control plays a major role in integrated control. For the future, it is necessary to produce and use more effective and more selective pesticides.

What kind of pesticides are required for the future?
They must have high activity, be safe and without harmful effects to the environment. I think this statement is a precise description of the requirements of future pesticides.

Highly active capability is the basic trend of the development of pesticides. In comparison with pesticides used twenty years ago, the dosage of today's pesticides has obviously decreased. Future pesticides should be used in even lower dosages.

To be safe and without harmful effects to the environment is also a basic requirement for pesticides. The manner of evaluating their safety and effects is very important; we must find better ways than we have at present to make such evaluations.

One problem that $I$ wish to mention here is that of organic chlorine compounds. Large amounts of BHC and DDT are still used in China. This situation must be changed in the future and these insecticides gradually replaced by others.

As I mentioned above, insecticides account for the largest portion of pesticides produced. I think this will continue to be the situation for a long period because the most important thing at the moment in China is to control insects and ensure a good harvest. The quantity of fungicides and herbicides must also be increased, however, to meet the requirements of the farmer.

In addition to an increase in the production of pesticides, their quality must be improved. Resistance of pests and plant diseases to some pesticides is a problem that the world is finding it difficult to solve. Various ways may be used in addressing this problem. As well as searching for new pesticides against resistant pests and finding improved methods of application, formulation improvement is also needed. Mixtures of different pesticides are always more active than the single pesticide. For example, some organic phosphorous insecticides mixed with organic chlorine compounds or carbamates would be more active than the one substance alone.

Finally, I wish to relate some words on pesticide formulation. In my opinion, the formulation of pesticides is one key to the improvement of pesticide activity; it also is a good way to prolong the remaining activity and to decrease the toxicity to mammals. For example, a slow release or controlled release formulation is a good way of improving the property of a pesticide. Although this kind of formulation is not yet popularly used, I think it has hope for the future. 